\title{
TESTE DE USABILIDADE DE UMA NARRATIVA HIPERMIDIÁTICA POR MEIO DE AVALIAÇÃO EMOCIONAL (Emocard)
}

\author{
USABILITY TEST OF A HYPERMIDIATIC NARRATIVE THROUGH \\ EMOTIONAL EVALUATION (Emocard)
}

Silvia Quevedo, Dra. silviareginaquevedo@hotmail.com

Universidade Federal de Santa Catarina

Sabrina Bleicher, Doutoranda

sabrinableicher@gmail.com

Universidade Federal de Santa Catarina

Carlos Henrique Berg, Doutorando

henrique.berg@terra.com.br

Universidade Federal de Santa Catarina

Vânia Ulbrich, Dra.

vrulbricht@gmail.com

Universidade Federal de Santa Catarina

\section{RESUMO}

Ambientes Virtuais de Ensino Aprendizagem AVEAs usam narrativas hipermidiáticas para transmitir de várias formas o conhecimento. Essas narrativas são mediadas com humanos através de Interfaces Humano Computador e tais interfaces, por usarem metáforas reconhecíveis, podem apresentar barreiras à acessibilidade. Portanto, avaliar interfaces em busca de erros é importante no desenvolvimento de AVEAs. O AVEA inclusivo em desenvolvimento WebGD, com conteúdos de geometria descritiva para pessoas com deficiência auditiva, visual e sem deficiência, teve uma de suas narrativas hipermidiáticas testada com o método Emocard, teste de usabilidade com uso de emoções que valencia interfaces positiva ou negativamente. $O$ teste permitiu avaliar a interface apresentada, sendo valenciada positivamente pela maioria dos sujeitos.

Palavras-chave: narrativas hipermidiáticas; usabilidade; avaliação emocional.

\begin{abstract}
Learning Management systems LMS use hypermediatic narratives to convey knowledge in various ways. These narratives are mediated with bumans by Human Computer Interfaces and such interfaces, which use recognizable metaphors, may present barriers to the accessibility. Therefore, evaluate interfaces seeking for barriers is an important issue in the developing of LMSs. The inclusive LMS WebGD, is developed with contents of descriptive geometry for impaired people with hearing and visual disabilities and without impairment. One of this hypermidiatic narratives was tested with the method Emocard. This usability test with emotions valence interfaces positively or negatively. The test allowed to evaluate the interface presented, being valenced positively by most subjects.
\end{abstract}

Keywords: bypermedia narratives; usability; emotional evaluation

\section{INTRODUÇÃO}

Nas duas últimas décadas, as transformações das Tecnologias de Informação e Comunicação (TIC) ofereceram um novo cenário, que facilitou a troca de informações entre as pessoas. Conceitos como rede e ciberespaço consolidaram-se e as estruturas educacionais moldaram-se visivelmente de acordo com esse fenômeno global. Parâmetros que impulsionaram uma nova cultura educacional com diferentes ritmos de aprendizagem 
na web ofereceram à Educação a Distância $(\mathrm{EaD})$ novas possibilidades, que permitiram sua expansão (FRANÇA, 2009).

Moore e Kearsley (2011, p. 47) corroboram com o exposto ao destacar que, "do mesmo modo que cada geração anterior de tecnologia [correios, rádio, televisão, vídeo etc.] [...] produziu sua modalidade específica de organização de aprendizado a distância, a disseminação da tecnologia da internet estimulou novas ideias a respeito de como organizar [e apresentar] o ensino a distância".

Diferente dos recursos tradicionais (como o livro, que por muito tempo foi o principal meio de armazenamento do conhecimento e onde as informações são geralmente ordenadas em páginas sequenciais para serem lidas de modo linear), nas tecnologias digitais os conteúdos estão interconectados em rede, permitindo que seus usuários leitores possam escolher qual caminho seguir ou navegar por meio do conhecimento previamente armazenado e estabelecido pelo projetista autor. (SCHWARZELMÜLLER, 2005).

A narrativa hipermidiática encaixa-se nesse molde proposto pela web, que une som, imagem e movimento em um ambiente interativo. O tradicional "começo, meio e fim" de uma história, em perspectiva linear, tem, nesse recurso, seu percurso alterado por outras possibilidades de conexão de sentido e o leitor passa a ser o dono de seu próprio caminho de leitura. A chamada "não linearidade", ou seja, o estabelecimento de uma "desordem" na "ordem" de se demonstrar os fatos é uma característica desse tipo de narrativa.

O uso de diferentes narrativas, enquanto tipologia de texto, é outro acréscimo ao tema, uma vez que o aprendiz pode ter acesso ao mesmo conteúdo demonstrado de diferentes formas. Em ambiente virtual a demonstração desse conteúdo pode se dar de acordo com o perfil de escolha de cada sujeito.

Acrescenta-se a isso o fato de que, segundo Filatro (2008, p. 72), "a memória humana tem capacidade limitada de processamento". De acordo com a autora (2008, p. 72), o entendimento, à compreensão daquilo que se vê e se ouve depende da "carga cognitiva intrínseca (dificuldade inerente ao material, como: quantos elementos são representados e qual a relação entre eles) e da carga cognitiva extrínseca (como a mensagem é organizada e apresentada)".

Para Filatro (2008), quando uma informação é apresentada em diversas modalidades sensoriais - textual, visual, auditiva -, como é o caso da narrativa hipermidiática, são ativados diferentes sistemas de processamento e a capacidade da memória de trabalho é estendida.

Assim, a combinação de uma imagem com sua designação verbal ou auditiva, por exemplo, é mais facilmente lembrada do que a apresentação dessa mesma imagem duas vezes ou a repetição dessa designação verbal várias vezes, de forma isolada.

Nos recursos didáticos voltados ao ensino e aprendizagem, de modo geral, e na $\mathrm{EaD}$, em particular, normalmente, há várias fontes de informação competindo pela limitada capacidade de processamento e, por isso, a narrativa hipermidiática apresenta-se como um recurso capaz de estruturar essas informações de modo a facilitar a construção do conhecimento, podendo ser vista, como um recurso a ser utilizado para enriquecer o espaço pedagógico.

Com a perspectiva de enriquecer o espaço pedagógico, é possível inserir ainda mais uma questão nesse cenário: a de que a linguagem em hipermídia, por se utilizar de diferentes linguagens, apresenta-se como um recurso capaz de atingir diferentes perfis cognitivos, aspecto dos mais relevantes para a EaD.

A EaD, por se tratar, por definição, de uma modalidade educacional na qual "a mediação didático-pedagógica nos processo de ensino e aprendizagem ocorre com a utilização de meio e tecnologias de informação e comunicação, com estudantes e professores desenvolvendo atividades educativa em lugares ou tempos diversos" (BRASIL, 2005), é capaz de incorporar em um único curso um número de alunos infinitamente maior que o ensino presencial. 
Por essa razão, abrange diferentes perfis de alunos. Nesse sentido, apresenta-se como uma oportunidade para as pessoas com necessidades especiais, porque oferece a conveniência de um aprendizado livre das complicações de acesso que surgem quando estas precisam assistir presencialmente às aulas. (MOORE E KEARSLEY, 2011).

Contudo, segundo Litto (2009, p. 120), centra-se neste ponto um grande problema da EaD no Brasil. Nas palavras do autor: "[há] pouco esforço para oferecer um "cardápio" rico de atividades educacionais a distância a uma significativa parte da população com necessidades especiais, e com os mesmos direitos dos demais cidadãos de adquirir novas capacitações e a sua certificação".

Litto (2009) vai ao encontro do censo do IBGE (2010), que revelou a existência de 45.623.910 pessoas com diferenças físicas e sensoriais, o equivalente a $23,9 \%$ da população brasileira. Tiziotto e Oliveira Neto (2010, p. 2) confirmam a ideia de Litto ao declarar que: "[...] no que se refere à educação, há escassez de iniciativas e projetos concluídos em nosso país, os quais considerem, em sua totalidade, as especificidades de nossos educandos de acordo com perfis e aspectos pessoais, culturais, sociais etc.".

Nessa lacuna de recursos educacionais inclusivos insere-se o WebGD Acessível, fundamentado a partir do projeto Educação Inclusiva: Ambiente Web Acessível com Objetos de Aprendizagem para Representação Gráfica, com apoio da CAPES e CNPq. Com objetivo de desenvolver um AVEA inclusivo voltado ao ensino da Representação Gráfica, o ambiente deve incluir pessoas com diferenças auditiva e visual. Este artigo descreve a experiência de um teste de usabilidade ${ }^{\mathrm{i}}$ com uso de emoções de uma das narrativas hipermidiáticas desenvolvidas no âmbito do referido projeto.

\section{MÉTODO}

O experimento visou identificar as valências de uma narrativa hipermidiática através de um teste de usabilidade com uso de emoções, permitindo detectar se há alguma barreira à compreensão do conteúdo. Como método, foi escolhido o Emocard (DESMET ET AL, 2001), que consiste em um cartão de respostas emocionais não verbais.

O experimento realizado foi estruturado com base nas pesquisas desenvolvidas por Han (2000), que propõe novas dimensões para avaliar a usabilidade de um sistema, nos quais os aspectos subjetivos têm maior importância que testes de desempenho. Segundo o autor, duas dimensões podem ser avaliadas: Dimensão de Desempenho e Dimensão de Imagem/Impressões. Como o objetivo da pesquisa foi avaliar uma narrativa hipermidiática, selecionou-se a segunda dimensão para avaliação, ou seja, buscou-se identificar as dimensões de imagens e impressões.

A Dimensão de Imagem/Impressões se subdivide, segundo Han (2000), em: (I) senso básico; (II) descrição da imagem; e (III) avaliação de sentimentos. A subdivisão "avaliação de sentimentos" (subdivisão escolhida para avaliação na pesquisa aqui apresentada) busca identificar a satisfação do participante por meio das valências positivas ou negativas provocadas pelo uso da ferramenta.

A teoria cognitiva proposta por Ortony, Clore e Collins (em TZVETANOVA; TANG; JUSTICE, 2007) define emoções como reações "valenciadas" (positiva ou negativa) resultantes de alguma situação. Similarmente Ancker, Chan e Kukafka (2012) descrevem respostas emocionais como negativa, positiva ou mista. Além disso, a valência das emoções depende de uma situação desejável, com metas e preferências.

A ferramenta adotada para valenciar o ambiente foi o Emocard, proposto por Desmet et. al (2001) a fim de avaliar as emoções em relação à narrativa apresentada. Os autores descobriram que as emoções são difíceis de verbalizar e que pedir para os usuários descreverem sua resposta emocional implica envolvimento cognitivo. Ao considerar esse fato, o autor desenvolveu um método de autorrelato não verbal que busca identificar as emoções em produtos ou interfaces e denominou-o Emocard (Figura 1). 


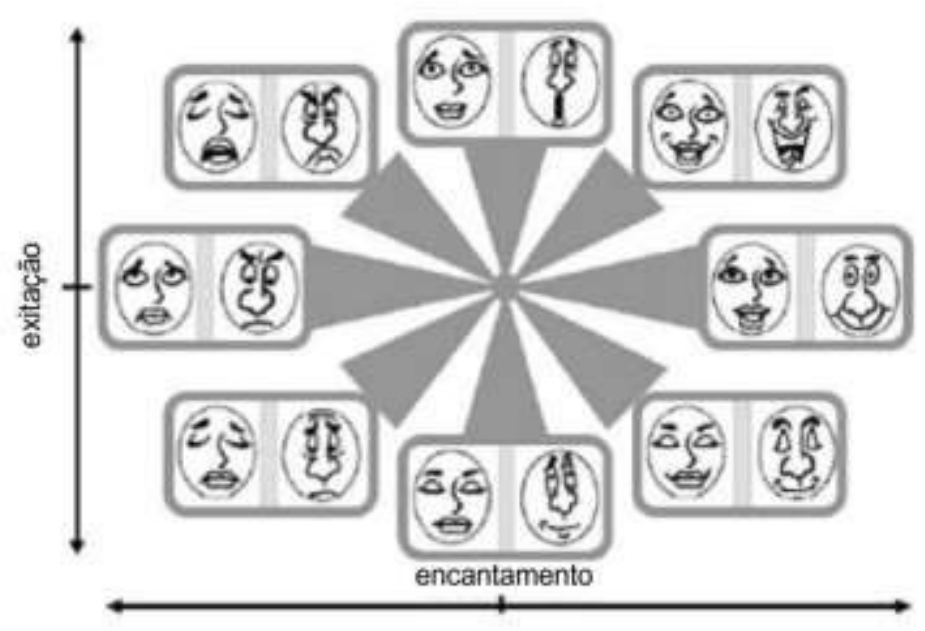

Figura 1 - Emocard

Fonte: Desmet et. al., 2001.

Neste método, é realizada a seleção de emoticons, colocados em uma tabela, combinando duas diferentes dimensões de emoções (AGARWAL, MEYER, 2009), com o objetivo de medir estados emocionais generalizados (TÄHTI et. al, 2004). As vantagens do método centram-se na rapidez e na simplicidade de utilização. De acordo com a pesquisa de Tähti et. al (2004) esse método foi bem sucedido para medir respostas de consumidores de diferentes produtos (TÄHTI et. al, 2004).

O teste de usabilidade da narrativa escolhida através do Emocard permitiu identificar as valências positivas e negativas das emoções sentidas pelos participantes. Os resultados foram analisados usando o modelo de Tähti et. al. (2004).

\subsection{A aplicação do experimento}

A apresentação da narrativa foi organizada e aplicada em 2 de agosto de 2012 junto a alunos de pós-graduação, predominantemente das áreas de Educação e Linguística, participantes de disciplina oferecida pela Universidade Federal de Santa Catarina (UFSC). Intitulada PGI 410093 - Tópicos Especiais em Análise do Discurso: Análise Crítica do Discurso, a disciplina consistiu em uma semana de encontros para discussão teórica e aplicação prática dos principais constructos da Análise Crítica do Discurso (ACD).

Construída no software InDesign, a narrativa hipermidiática foi elaborada sob a forma de um conto, mais precisamente uma fábula, com ilustrações, fotografias e hiperlinks contendo explicações sobre conteúdos de Projeção Cilíndrica Ortogonal. A narrativa foi apresentada aos alunos por meio de uma projeção em tela na sala de aula. A figura 2 mostra o print screen inicial da narrativa hipermidiática testada. 


\section{o gato, o cavalo e um sonfo}

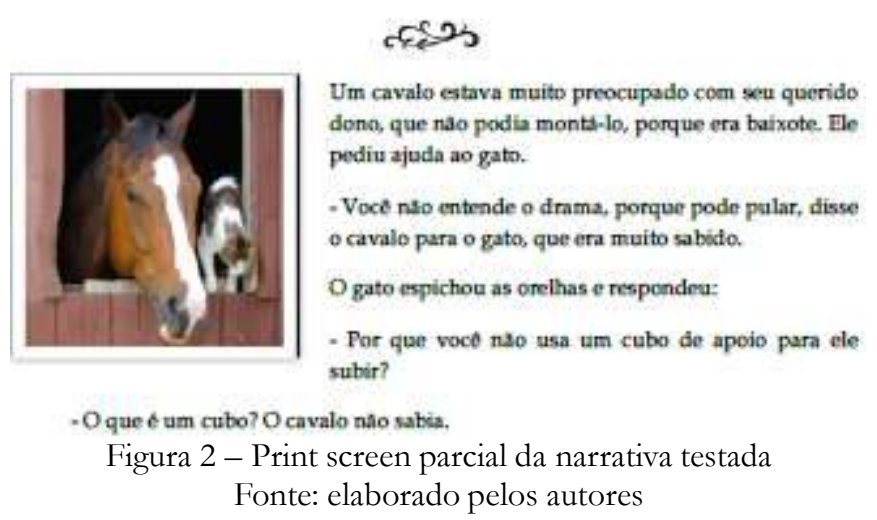

A fábula em questão tem como título "O gato, o cavalo e um sonho" conta a história de um cavalo que estava muito preocupado com o fato de seu dono ser muito baixo e não conseguir montá-lo. O gato sugere ao cavalo construir um cubo e, depois, uma escada, para o que precisa também de um paralelepípedo. O cavalo, que nunca tinha ouvido falar sobre o tema, sentiu-se perdido.

A história adota um caminho alternativo quando os dois animais chamam o João de Barro para ajudar na construção da escada. Depois de retornar para o conteúdo principal da narrativa, o usuário depara-se com dois finais. No primeiro deles, o cavalo constrói a escada; no segundo fracassa em seu intento.

Para cada final há uma "moral" correspondente: o fato de o cavalo construir a escada enseja a frase de Walt Disney (1901-1966): "Se você pode sonhar, você pode fazer". Já no segundo caso, como o cavalo não consegue construir a escada por não haver anotado o que os amigos disseram, a frase final é um provérbio do filósofo chinês Confúcio: "Ouço, esqueço. Escrevo, lembro. Faço, aprendo".

A apresentação do conto e o teste de usabilidade da narrativa hipermidiática teve início às $11 \mathrm{~h} 32 \mathrm{~min}$ e encerrou às $12 \mathrm{~h} 00 \mathrm{~min}$. Em primeiro lugar, foi apresentado o projeto de pesquisa no qual a narrativa hipermidiática se insere. A seguir, foi explicado, de modo sucinto e objetivo, conceitos relacionados às narrativas hipermidiáticas acessíveis.

Às 11h44min, o Emocard foi distribuído e explicado. A explicação foi breve e objetiva. A experiência foi acompanhada por dois pesquisadores-observadores, que anotaram as reações do grupo em meio à discussão que se seguiu à marcação dos Emocards. Após a apresentação da narrativa houve a distribuição das cédulas com o Emocard. Cada participante assinalou qual das expressões refletidas nos emoticons era mais próxima da sua.

\section{RESULTADOS}

Quanto a avaliação da narrativa, duas análises puderam ser feitas durante o experimento. A primeira refere-se às observações anotadas pelos pesquisadoresobservadores sobre as percepções dos alunos frente ao recurso apresentado, a narrativa hipermidiática.A segunda é a avaliação das respostas ao Emocard.

No que se refere às percepções dos alunos frente ao recurso apresentado, observou-se que consideraram confusa a não linearidade da narrativa. Expôs-se que os hiperlinks que levavam a diferentes finais poderiam confundir quem aprecia a linearidade tradicionalmente presente em contos e histórias.

A aplicação do teste de usabilidade através do Emocard junto aos sujeitos da pesquisa resultou em 21 cartões respondidos por seis homens e 15 mulheres. Com base nas quantidades assinaladas pôde-se plotar os resultados do Emocard e gerar um gráfico para visualizar os resultados. 
A Figura 3 apresenta os resultados das valências geradas junto ao público masculino, em que se percebe a concentração de emoções de cinco valências positivas e uma neutra (veja numeração na figura). Não houve valência negativa.

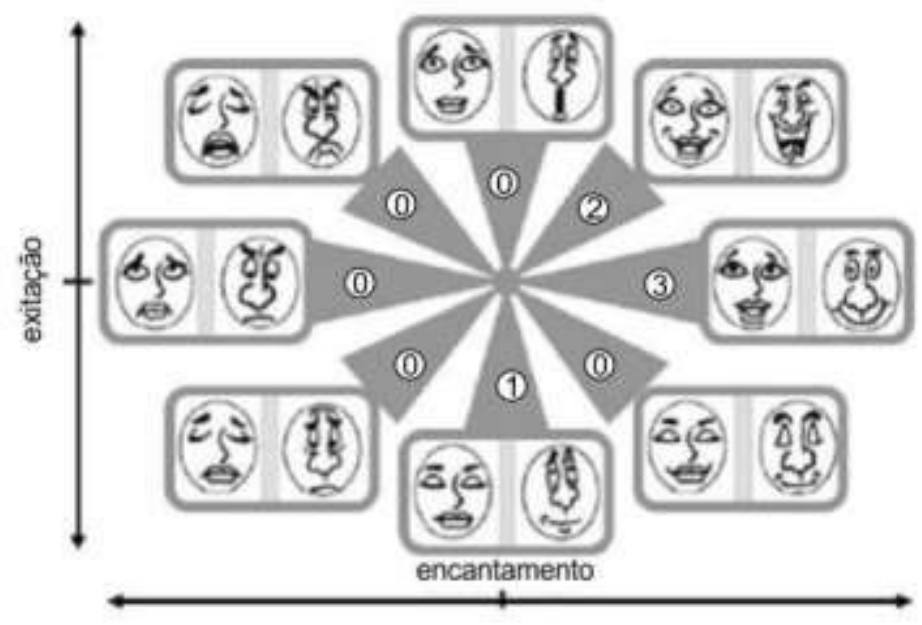

Figura 3 - Avaliação das emoções do público masculino Fonte: Elaborado pelos autores, 2012.

Junto ao público feminino onze de 15 citações foram valenciadas positivamente, houve duas respostas de valência negativa e duas neutras. (Figura 3).

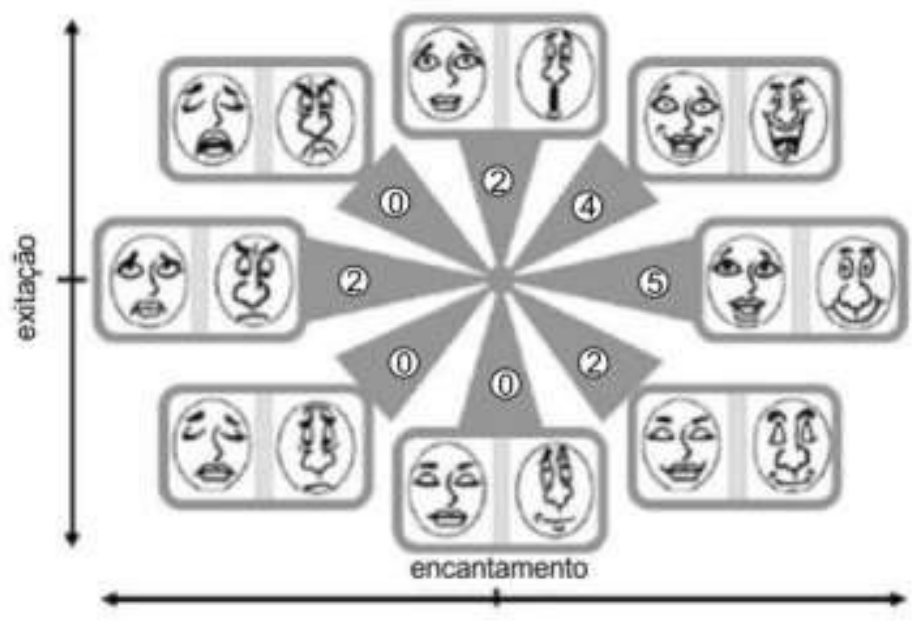

Figura 4- Avaliação das emoções do público feminino Fonte: Elaborado pelos autores, 2012.

O experimento demonstrou a eficiência do Emocard, apontando as valências da narrativa hipermidiática. Assim, a experiência de aferir as valências positivas e negativas dos participantes demonstrou que o conto foi aprovado para exposição do conteúdo de Projeção Cilíndrica Ortogonal.

Não foram identificados ruídos ou barreiras à compreensão do conteúdo. Como extensão da pesquisa, poder-se-ia investigar as respostas com valências negativas e neutras a fim de identificar que ruídos e barreiras que causaram a insatisfação. $O$ experimento também identificou que o uso de hiperlinks em narrativas hipermidiáticas pode prejudicar o entendimento da mensagem. 


\section{DISCUSSÃO}

Se para o receptor, a narrativa em hipermídia representa uma revolução diante da linearidade, também o autor é convocado a encontrar novas formas de expressão para manter desperto o interesse do receptor. Caminhar pelo labirinto exige um receptor ativo. Supõe-se que ao escolher nexos e interferir na obra, com a chance de criar novas conexões, o receptor de hipermídia seja potencialmente um criador.

As características da hipermídia, segundo Schwarzelmüller (2005), agregam vantagens a esse recurso em relação aos recursos tradicionais e lineares de produção, disseminação e armazenamento de conhecimento, tais como:

- $\quad$ partes do mesmo documento podem ser referenciadas de vários lugares;

- $\quad$ as ideias podem ser expressas com pouca sobreposição ou duplicação;

- $\quad$ as referências estão embutidas no documento tornando a informação consistente; e

- $\quad$ vários autores podem cooperar na criação de um mesmo documento.

Contudo, se é certo que a hipermídia traz, tanto ao autor como ao receptor, infinitas possibilidades de não linearidade à narrativa, também é relevante considerar que esses novos hábitos de leitura propugnados pela narrativa hipermidiática podem levar ao desconcerto, com a quebra da estrutura sem um final preciso esperado. (RODRÍGUEZ, 2006).

A eficácia da narrativa hipermidiática para transmissão do conhecimento se estabelece em um campo ainda controverso, porém, como toda linguagem, requer um momento de desenvolvimento técnico para o domínio dos mecanismos expressivos (MURRAY, 2003, SANTAELLA, 2007).

Dessa forma, ou com variações do mesmo tema, a sequência fora de ordem ameaça sequestrar a coesão e a coerência de um texto, causando ruído ao entendimento da mensagem. O ruído, por sua vez, comprometerá o significado do que se quer dizer, prejudicando o ato da comunicação, além de afetar a verossimilhança (efeito do real) que uma narrativa pode e deve oferecer.

França (2009, p.62) destaca a importância de se compreender os ambientes hipermidiáticos de aprendizagem e suas utilizações "não meramente como demonstrações de um aparato tecnológico, mas como outra maneira de assimilar e representar as novas formas didáticas e educacionais da contemporaneidade [...]". Para o autor, a narrativa hipermidiática - no âmbito educacional e principalmente para a modalidade a distância representa, não só um mecanismo tecnológico, mas um recurso que possibilita, viabiliza e facilita a construção do conhecimento.

A eficácia da narrativa hipermidiática para transmissão do conhecimento se estabelece em um campo ainda controverso, porém, como toda linguagem, requer um momento de desenvolvimento técnico para o domínio dos mecanismos expressivos (MURRAY, 2003, SANTAELLA, 2007).

Um dado importante talvez seja observar que a narrativa em hipermídia se faz antes sobre o andar do receptor do que sobre o caminho em si, sem imposições prévias do autor, o que permite uma espécie de personalização do relato. Segundo Rodríguez (2006), existe uma natural habilidade no ser humano de estabelecer conexões, qualidade que promoveria o ato criativo. Por essa razão considera-se como relevante o potencial da narrativa em hipermídia para a produção e disseminação de informações

\section{CONSIDERAÇÕES FINAIS}

O debate das ideias clama por um 'devir' à narrativa hipermidiática, verificando-se sua construção a partir de como as pessoas expressam suas experiências, contando-as por intermédio de suas escolhas. 
Somente ultrapassado o período de "pioneirismo" é que uma nova linguagem propicia domínio de uso. Com a narrativa hipermidiática não é diferente, pois a união da narrativa em forma de hipertexto com sistemas multimídia implica outra perspectiva estética dentro das expectativas da interdisciplinaridade, região epistemológica na qual se situam os estudos em hipermídia.

$\mathrm{O}$ uso do Emocard permite que se avalie as valências positivas e negativas de uma interface. A identificação de valências permite identificar o que há de positivo e o que há de negativo no ambiente. As valências negativas podem indicar onde existem problemas de compreensão e desse modo permitem aos desenvolvedores promover as correções necessárias.

Em conclusão, por meio do Emocard foi possível avaliar a narrativa hipermidiática com 21 sujeitos, seis homens e 15 mulheres, obtendo 16 valências positivas. Com este resultado pode-se considerar que a narrativa hipermidiática avaliada teve sua usabilidade valenciada positivamente, com poucas barreiras à compreensão.

\section{REFERÊNCIAS}

AGARWAL, A.; MEYER, A.. Beyond Usability: Evaluating Emotional Response as an Integral Part of the User Experience. In: CHI 2009, 2009, Boston. New Usability Metrics and Methods. Boston: Acm, 2009. p. 2919 - 2930.

ANCKER, J. S.; CHAN, C.; KUKAFKA, R. Interactive Graphics for Expressing Health Risks: Development and Qualitative Evaluation. Journal Of Health

Communication: International Perspectives, Londres, v. 5, n. 14, p.37-41, 23 maio 2012.

BRASIL. Decreto 5.622, de 19 de dezembro 2005. Regulamenta o art. 80 da Lei ${ }^{\circ}$ 9.394, de 20 de dezembro de 1996, que estabelece as diretrizes e bases da educação nacional. Disponível em:

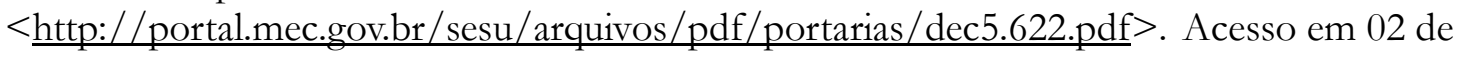
dezembro de 2012.

DESMET, P., OVERBEEKE, C.; TAX, S. Designing Products with Added Emotional Value; Development and Application of an Approach for Research through Design. The Design Journal, 4(1), 32-47, 2001.

DESMET, P.; HEKKERT, P. Framework of product experience. International Journal of Design 1 (1), 2007.

FILATRO, A. Design instrucional na prática. São Paulo: Person Education do Brasil, 2008.

FRANÇA, G. Os ambientes de aprendizagem na época da hipermídia e da Educação a Distância. Perspectivas em Ciência da Informação, v. 14, n. 1, p.55-65, jan./abr. 2009.

HAN, S. H. Usability of consumer electronic products. International Journal Of Industrial Ergonomics, Pohang, n. 28, p.143-151, 18 jan. 2000.

IBGE. Censo 2010. Disponível em: < http:/ / www.censo2010.ibge.gov.br/>. Acesso em 20 de maio de 2012.

ISO. International Organization For Standardization. International Organization For Standardization. Norma ISO 9241-11: 1998. Genebra: International Organization For Standardization, 1998. 22 p.

KAKASEVSKI, G. Evaluating Usability in Learning Management System Moodle. In: INT. CONF. ON INFORMATION TECHNOLOGY INTERFACES, 30., 2008, Cavtat. ITI 2008. Cavtat: Iti 2008, 2008. p. 613 - 618.

LITTO, F. M. O Retrato Frente e Verso da Aprendizagem a Distância no

Brasil 2009. ETD: Educação Temática Digital, v. 10, 2009.

MOORE, M G.; KEARSLEY, G. Educação a Distância: uma visão integrada. São Paulo: Cengage Learning, 2011. 
MURRAY, J. Hamlet no holodeck: o futuro da narrativa no ciberespaço. São Paulo: Itaú Cultural: Unesp, 2003.

NIELSEN, J. e LORANGER, H. Usabilidade na Web: projetando web sites com qualidade, Rio de Janeiro: Elsiever, 2007. 406 p.

NIELSEN, J. e MOLLICH, R. 1990. Heuristic evaluation of User interfaces. CHI'90 Proceedings. 249-256.

NIELSEN, J. Designing web usability: The practice of simplicity. Indianapolis: Nwe Riders Publishing, 1995.

ORTONY, A., CLORE, G.L., COLLINS, A.: The Cognitive Structure of

Emotions. Cambridge University Press, Cambridge, UK (1988)

RICHTEL, M. Uso excessivo de dispositivos digitais pode causar fadiga cerebral. New York Times.G1. Ciência e Saúde. Disponível em http://g1.globo.com/ciencia-e-saude/noticia. Acessado em 03 set. 2010.

RODRÍGUEZ, J.A. El relato digital: hacia um nuevo arte narrativo. Bogotá: Pontificia Universidad Javeriana, 2006. Disponível em http:/www.javeriana.edu.co/relato_digital/r_digital/teoria/teoria_index.htm. Acessado em 03 jun. 2010.

SANTAELLA, L. Linguagens líquidas na era da mobilidade. São Paulo: Paulus, 2007.

SCHWARZELMÜLLER, A. F. Sistemas hipermídia facilitando a assimilação da informação. VI Cinform - Encontro Nacional de Ensino e Pesquisa em Informação. Universidade Federal da Bahia. Salvador - BA. 2005. Disponível em: $<$ http://www.cinform.ufba.br/iv_anais/artigos/TEXTO06.HTM>. Acesso em 06 de maio de 2012.

TÄHTI, M. et al. Mobile Forum. In: AUSTRALIAN CONFERENCE ON COMPUTER-HUMAN INTERACTION, 1., 2004, Wollongong. Catching Emotions Elicited by Mobile Services. Wollongong: University Of Oulu, 2004. p. 1 - 10.

TIZIOTTO, A.A. OLIVEIRA NETO, J. D. Design Universal: solução para a acessibilidade no ensino superior a distância. In: Congresso Internacional de Educação a Distância, 2010, Foz do Iguaçu. 16 Congresso Internacional de Educação a Distância, 2010.

TORREZZAN, C.; BEHAR, P. A. Parâmetros pedagógicos de materiais educacionais digitais do ponto de vista do design pedagógico. In: BEHAR, Patrícia Alejandra et al. Modelo Pedagógicos em Educação a Distância. Porto Alegre: Artmed, 2009. Cap. 2, p. 33-65.

WALKER, S.; PRYTHERCH, D. How Is It for You?: A Case for Recognising User Motivation in the Design Process. In: LNCS 4868, 2008., 2008, Berlin. Affect and Emotion in HCI. Berlin: Springer-verlag, 2008. p. 130 - 141.

TZVETANOVA, S.; TANG, M.; JUSTICE, L. Emotional Web Usability Evaluation. Human-Computer Interaction: HCII 2007, Berlin, n. , p.1039-1046, 2007. 


\title{
AGRADECIMENTOS
}

\section{A CAPES CNPQ}

\begin{abstract}
i A conceituação de usabilidade está diretamente ligada ao uso de produtos ou softwares por parte de usuários. Como definição formal, usabilidade refere-se à capacidade dada aos usuários de um produto em particular para atingir objetivos específicos com eficácia, eficiência e satisfação em um determinado contexto de uso" (ISO, 1998). Nielsen e Loranger (2007, p. xvi) conceituam a usabilidade como: "[...] um atributo de qualidade relacionado à facilidade do uso de algo. Mais especificamente, refere-se a rapidez com que usuários podem aprender a usar alguma coisa, a eficiência deles ao usá-la, o quanto lembram daquilo, seu grau de propensão a erros e o quanto gostam de utilizá-la”. Os testes de usabilidade consistem em identificar barreiras no uso de um produto ou sistema, o que os torna essenciais para garantir um grau mínimo de usabilidade (NIELSEN e LORANGER, 2007). Os testes de usabilidade podem incorporar diversas técnicas - como vídeo feedback, gravação de tela, registro de arquivos, o método thinking-aloud, eye-tracking, entre outros - e diferentes métodos - como questionários, entrevistas, revisão por especialistas, pesquisas online etc.
\end{abstract}

